\title{
RAÇA, GÊNERO E SEXUALIDADE EM LIVROS DIDÁTICOS
}

\author{
As políticas do livro didático e identidades sociais de \\ raça, gênero, sexualidade e classe em livros didáticos \\ FERREIRA, Aparecida de Jesus (organizadora). \\ Campinas, SP: Pontes, 2014. 246 p.
}

Vive-se atualmente no Brasil uma acalorada discussão acerca da chamada "ideologia de gênero". Neste contexto, o livro As políticas do livro didático e identidades sociais de raça, gênero, sexualidade e classe em livros didáticos, organizado por Aparecida de Jesus Ferreira², mostra-se relevante e atual por levar a discussão sobre gênero e raça/etnia para um instrumento central da educação formal: os livros didáticos.

Uma recorrência entre as autoras 3 é justamente o papel primordial que os livros didáticos possuem no processo de ensino-aprendizagem. Esses manuais continuam a ser, por vezes, o único material que orienta as práticas pedagógicas em sala de sala, sendo, portanto, uma voz de poder, de autoridade. Possuem a capacidade de difusão e construção de valores, discursos e imagens, podendo, desse modo, contribuir para a quebra de paradigmas ou para a manutenção de estereótipos e estigmas. Enfim, as autoras alertam para o fato de os livros didáticos serem um instrumento que desempenha um papel importante no processo de (re)produção de práticas sociais, assim como possuem potencial para gerar questionamentos e resistência a essas práticas.

Sabendo do potencial que os manuais escolares possuem de incitar reflexões sobre práticas sociais, um dos grandes eixos do projeto "Escola sem homofobia", lançado no governo Lula, foi a elaboração de material didático, isto é, a formulação do "kit de combate à homofobia" - desenvolvido por uma coalização de ONGs do movimento LGBT e apoiado pelo Ministério da Educação - para ser distribuído nas escolas públicas. A veiculação do material, entretanto, foi suspensa em 2011,

1 Trata-se de uma categoria acusatória que serve de eixo articulador de diferentes grupos conservadores (católicos, evangélicos, laicos) que pretendem barrar avanços dos direitos humanos concernentes a demandas envolvendo direitos sexuais e reprodutivos. Assim, instaura-se uma perseguição às ideias que defendem a igualdade entre homens e mulheres, bem como à educação sexual, ao combate à homo-lesbo-bi-transfobia e ao reconhecimento de identidades não heterossexuais. A esse respeito, ver: Facchini e Sívori (2017), Miskolci (2018) e Miskolci e Campana (2017).

2 A organizadora é doutora em Educação de Professores pela Universidade de Londres, Inglaterra, e professora da Universidade Estadual de Ponta Grossa, onde atua na graduação em Letras e no mestrado em Estudos da Linguagem.

3 Uma vez que 9 das 15 pessoas que assinam os capítulos do livro são mulheres, usar-se-á o plural no feminino e não no masculino genérico. Do mesmo modo, utilizar-se-á o feminino genérico no decorrer do texto.

\section{Vítor Lopes Andrade}

Mestre em Antropologia Social pela Universidade Federal de Santa Catarina.

E-mail: vitorlandrade@yahoo.com.br 
antes de chegar às escolas. Isso ocorreu devido à polêmica causada na Câmara dos Deputados do Congresso Nacional, onde a proposta foi acusada de incentivar o "homossexualismo" entre crianças e adolescentes, passando a ser mais conhecida na mídia, pejorativamente, como "kit gay". O material, portanto, foi vetado. Entretanto, quais representações acerca de identidades sociais de raça, gênero e sexualidade os livros didáticos que estão atualmente nas escolas brasileiras trazem às alunas? É a resposta a esta pergunta que o livro organizado por Aparecida de Jesus Ferreira traz às leitoras.

Deve ser destacado o caráter de interseccionalidade que o livro evidencia ao abordar as temáticas de gênero, sexualidade, raça e, em menor escala, classe social. A interseccionalidade, como se sabe, foi formulada como questão, primeiramente, pelo feminismo negro e baseia-se na ideia de que as opressões (sexismo, racismo, homofobia) trabalham juntas produzindo injustiças (Collins, 2009:21). Entretanto, se o livro como um todo se apresenta de maneira interseccional, o mesmo não pode ser dito sobre os capítulos em separado, que, no geral, focam a análise ou na questão da raça ou na questão do gênero.

No que diz respeito às representações de gênero e sexualidade em livros didáticos, dois capítulos se sobressaem: o escrito por Rogério Tilio e Elio Marques de Souto Junior e o assinado por Ariovaldo Lopes Pereira. O primeiro consiste em análise dos documentos oficiais do Plano Nacional do Livro Didático acerca das palavras "gênero" e "sexualidade", enfocando os manuais de Língua Estrangeira Moderna. Os autores mostram que "gênero", nestes documentos, refere-se majoritariamente a gêneros textuais/discursivos e não a concepções acerca do que se entende socialmente por ser mulher ou homem. Em relação à temática da sexualidade nos documentos em questão, os autores revelam que as ocorrências aludem a uma perspectiva meramente biológica: perigos das Doenças Sexualmente Transmissíveis e alerta para o controle de natalidade, por exemplo.

O capítulo de Ariovaldo Lopes Pereira evidencia como os livros didáticos de língua estrangeira representam mulheres e homens na família, no mundo do trabalho e no esporte. Em relação às representações de família, todos os livros analisados se mostram conservadores, no sentido de que trazem imagens tradicionais: não representam famílias de pais separados, relacionamentos entre pessoas do mesmo sexo ou pais casados mais de uma vez. Os homens são geralmente apresentados como os "provedores do lar" e autoridades máximas da família, enquanto às mulheres cabem os papéis de boa esposa e mãe dedicada. Sobre o mundo do trabalho, o autor afirma que ainda são evidentes os discursos que exaltam a supremacia masculina no exercício de profissões de maior prestígio social e financeiro. Já em relação às representações em esportes, a análise mostrou a predominância de personagens masculinos praticando esportes radicais e de maior visibilidade na sociedade. Além disso, os ídolos esportivos mencionados nos livros são homens, ao passo que as mulheres esportistas aparecem anonimamente.

Percebe-se, portanto, através das análises, que os livros didáticos - e, dessa forma, a própria escola - reproduzem e legitimam a heteronormatividade presente 
na sociedade, bem como a distinção de papéis sociais tidos como masculinos e femininos. Ademais, mantém-se um discurso biológico acerca de sexualidade e relações sexuais.

A problematização acerca de classe social é encontrada no capítulo escrito por Mariana Mastrella-de-Andrade e Jayfferson Alves Rodrigues. As autoras evidenciam que uma temática recorrente em livros didáticos são os lugares que podem ser visitados por turistas durante o período de férias, sendo que na maioria das vezes são apresentados destinos internacionais. Assim, Mastrella-de-Andrade e Rodrigues concluem que há uma elitização do lazer nos livros didáticos, já que existe uma valorização dos destinos turísticos tidos como famosos, que oferecem experiências de viagem de alto custo.

São os capítulos referentes às análises das representações de raça em livros didáticos que se mostram como os mais perspicazes. Um item a ser pontuado é a ausência ou sub-representação de personagens negras. Aparecida de Jesus Ferreira traz dados de uma de suas pesquisas acerca de representações de brancas e negras em um dos livros didáticos de Inglês mais vendidos no Brasil: são 321 representações de homens brancos em contraposição a 24 de homens negros e 246 representações de mulheres brancas contra somente 13 de mulheres negras. De acordo com a autora, esses dados evidenciam o poder simbólico de ser branco. Em outra pesquisa, agora em um livro didático de Espanhol, Ione da Silva Jovino afirma que apareceram 152 homens brancos e 33 homens negros e em relação às mulheres os números foram 127 para brancas e 56 para negras. Mastrella-de-Andrade e Rodrigues esclarecem (2014:155):

não queremos com isso afirmar que o simples fato de termos fotos ou textos de referência a pessoas negras já significaria mudança nas relações raciais [...] O que ressaltamos aqui, todavia, é que os apagamentos da existência de raças diferentes no livro didático contribuem para a reprodução e a manutenção das relações raciais com a supremacia e superioridade brancas, o que não promove a conscientização crítica sobre essa questão.

A ausência ou sub-representação de personagens negras não se dá somente em caráter quantitativo, mas também em situações valorizadas socialmente: poucas negras são apresentadas como construtoras do saber científico; via de regra, nas ilustrações de médicas e executivas nenhuma das pessoas é negra. De acordo com Aparecida de Jesus Ferreira, há uma representação estereotipada da negra e do negro como sendo bons somente em esportes, música e cinema. No geral, quando se trata da temática de profissões, o local onde os homens negros aparecem representados é nos times de futebol. Há, entretanto, exceções, ainda que poucas: em um livro didático de ciências, em imagens que ilustram temas específicos de conteúdo referentes ao corpo humano, o corpo negro foi utilizado e, no mesmo livro, foi representado 
através da imagem de médicos e cientistas negros; em um livro didático de Espanhol, na representação de crianças, há um menino negro caracterizado como cientista.

De acordo com a pesquisa de Ione da Silva Jovino, "houve um aumento na apresentação de personagens negros no livro didático, porém eles são retratados em situação de miséria e os brancos continuam sendo mais valorizados e se apresentam como representantes da espécie" (2014:124). Nota-se, assim, que a prevalência de personagens brancas as conota como padrão - como representantes "naturais" - da humanidade, o que tem sido conceituado como "branquitude normativa".

Ainda em relação às representações sobre raça em livros didáticos, é necessário destacar o capítulo de Paulo Vinicius Baptista da Silva, Rozana Teixeira e Tânia Mara Pacifico. Normalmente, em estudos com manuais escolares, as pesquisadoras realizam análise discursiva e/ou imagética. Estas três autoras, entretanto, realizaram um estudo sobre a percepção de alunas e alunos negras sobre as temáticas de raça nos livros didáticos. Pediram para as alunas desenharem a imagem mais recorrente que tinham de negras e negros nos livros, realizando, posteriormente, entrevistas. Os discursos racistas presentes nos livros foram percebidos pelas estudantes e atuam como uma forma de racismo institucional. Ficou evidente às autoras que persiste um discurso que representa a negra presa ao passado colonial da escravidão, uma vez que 12 dos 15 desenhos remetiam a isso e, em 11 deles, havia personagens negras "castigadas em tronco".

As políticas do livro didático e identidades sociais de raça, gênero, sexualidade e classe em livros didáticos revela que os manuais analisados apresentam estereótipos de gênero, sexualidade e raça, assim como a heteronormatividade e a branquitude normativa. Em vários momentos do livro as autoras argumentam, entretanto, que esses estereótipos podem (e devem) ser trabalhados em sala de aula, a fim de serem problematizados, criticados, discutidos. Ou seja, é possível, a partir de um discurso sexista e racista, criar um movimento de contestação. bell hooks, em relação à língua inglesa 'padrão', postula: "nós tomamos a língua do opressor e a viramos contra ela mesma. Nós fazemos das nossas palavras uma fala contra-hegemônica" (hooks, 2008: 863-864). Para se formarem esses contradiscursos, é necessário que as professoras estejam atentas às questões de gênero, sexualidade e raça, o que nem sempre acontece. Aparecida de Jesus Ferreira relata que a grande maioria das professoras com quem teve contato não percebia a falta de representação de pessoas negras nos livros didáticos (2014: 108). Nota-se, portanto, que é preciso incluir essas temáticas nas formações de professoras, a fim de que, tendo um posicionamento crítico sobre esses assuntos, elas possam questionar os estereótipos em sala de aula.

O livro organizado por Aparecida de Jesus Ferreira, aqui comentado, mostrase relevante e atual não só pelo momento histórico em que se vive no Brasil, mas também por não ser puramente um livro teórico-acadêmico. É evidente que as análises trazidas, a identificação de estereótipos, os exemplos dados, possuem grande valor científico. Mas o livro extrapola esse objetivo, sendo útil para professoras em geral - do Ensino Fundamental ao Ensino Superior -, para escritoras de manuais escolares e até mesmo para estudantes de línguas estrangeiras que utilizam livros 
didáticos; enfim, para todas aquelas que de alguma forma estejam envolvidas direta ou indiretamente com a educação formal.

\section{Referências bibliográficas}

COLLINS, Patricia Hill. (2009). Black Feminist Thought. Knowledge, consciousness, and the politics of empowerment. New York: Routledge Classics.

FACCHINI, Regina; SÍVORI, Horacio. (2017). "Conservadorismo, direitos, moralidades e violência: situando um conjunto de reflexões a partir da Antropologia”. Cadernos Pagu, n. 50: p. 1-18, maio-ago.

FERREIRA, Aparecida de Jesus (org.). (2014). As políticas do livro didático e identidades sociais de raça, gênero, sexualidade e classe em livros didáticos. Campinas, SP: Pontes.

hooks, bell. (2008). "Linguagem: ensinar novas paisagens/novas linguagens". Revista Estudos Feministas, n. 16, 3: p. 857-864, set-dez.

JOVINO, Ione da Silva. (2014). "Representação de negros e negras num livro didático de Espanhol: alguns apontamentos”. In: FERREIRA, Aparecida de Jesus (org.). As políticas do livro didático e identidades sociais de raça, gênero, sexualidade e classe em livros didáticos. Campinas, SP: Pontes, p. 121-141.

MASTRELLA-DE-ANDRADE, Mariana; RODRIGUES, Jayfferson. (2014). "A construção de identidades no livro didático de Inglês: classe social, raça e o Outro". In: FERREIRA, Aparecida de Jesus (org.). As políticas do livro didático e identidades sociais de raça, gênero, sexualidade e classe em livros didáticos. Campinas, SP: Pontes, p.143-161.

MISKOLCI, Richard. (2018). Exorcizando um fantasma: os interesses por trás do combate à "ideologia de gênero". Cadernos Pagu, n. 53: p. 1-14, maio-ago.

MISKOLCI, Richard; CAMPANA, Maximiliano. (2017). "Ideologia de gênero": notas para a genealogia de um pânico moral contemporâneo. Revista Sociedade e Estado, n. 32, 3: p. 725-747, set-dez.

Recebido: 27.06.2018

Aceito: $17 \cdot 10.2018$ 